\title{
Is Cancer Still the Villain, Even during COVID 19 Outbreak?
}

\author{
Aravindh Sivanandan Anand ${ }^{*}$, Mahadevan Rajagopalapillai', Abraham Eapen ${ }^{1}$, \\ Gopika Presenavarman1, Sachin Suseelan1, Induprabha Yadav', Gautham Aravind ${ }^{3}$ \\ ${ }^{1}$ Department of Radiation Oncology, Government Medical College, Trivandrum, India \\ ${ }^{2}$ Department of Surgery, Government Medical College, Trivandrum, India \\ ${ }^{3}$ Sree Gokulam Medical College, Venjarumoodu, Trivandrum, India \\ Email:^anandrt2006@yahoo.com
}

How to cite this paper: Anand, A.S., Rajagopalapillai, M., Eapen, A., Presenavarman, G., Suseelan, S., Yadav, I. and Aravind, G. (2020) Is Cancer Still the Villain, Even during COVID 19 Outbreak? Journal of Cancer Therapy, 11, 535-546. https://doi.org/10.4236/jct.2020.119046

Received: August 24, 2020

Accepted: September 21, 2020

Published: September 24, 2020

Copyright $\odot 2020$ by author(s) and Scientific Research Publishing Inc. This work is licensed under the Creative Commons Attribution International License (CC BY 4.0).

http://creativecommons.org/licenses/by/4.0/

\begin{abstract}
Background: Anxiety and depression are two common psychiatric conditions encountered in cancer treatment. Prevalence rate and risk factors show wide variations in different countries and the environment. COVID 19 outbreak has increased psychological disorders in general public and health workers. Whether this pandemic has increased the psychiatric morbidity in cancer patients needs to be addressed for planning strategies. Methods: This cross-sectional study was conducted in the Department of Radiation Oncology, a tertiary cancer centre in the state of Kerala, India. The aim was to assess hospital prevalence and risk factors of anxiety and depression among cancer patients during COVID 19 pandemic. Patients on treatment for cancer and willing for the study were recruited. Hospital Anxiety and Depression Scale (HADS), a self-assessment valid tool for screening both anxiety (HADS-A) and depression (HADS-D) are used. HADS-A \& D were calculated separately \& categorized as normal, borderline and abnormal with a score of $0-7,8-10 \& 11-21$ respectively. Separate structured questionnaire for COVID19 related questions and patient master file for patient \& treatment characteristics were used in risk assessment. Data were entered in an Excel sheet and SPSS version 22 for statistical analysis. Findings: 208 patients were included in this study. The overall prevalence rate of anxiety was $7.2 \%$, with borderline cases $4.3 \%$ and abnormal cases $2.9 \%$. The overall prevalence of the rate of depression was 5.3\% (3.4\% borderline \& $1.9 \%$ abnormal). Risk factors like age, sex, socioeconomic status, primary site, stage of the disease and default of disease had no statistical significance. Interpretation: The prevalence rate of anxiety and depression among cancer patients in this study is one among the lowest ever reported. COVID 19 outbreak has not brought any impact in the rate of psychological distress in our patients and the low
\end{abstract}


rate may be due to the robust medical care including mental health interventions and reassurance by the Government.

\section{Keywords}

Cancer, COVID 19, Anxiety, Depression, HADS Scale

\section{Introduction}

Anxiety and depression are the two common psychiatric conditions encountered in cancer treatment. Studies have shown that the prevalence of these two is high among cancer patients but in most instances, it goes unnoticed or undiagnosed. In India, studies have shown that the cancer patients have psychiatric morbidity either in the form of depressive disorder or in the form of generalized anxiety disorder as high as $43 \%-46 \%$ [1] [2]. The diagnosis of cancer itself is stressful and it can have a substantial impact on the mental health of the patient. The concern about the toxicity of treatment, uncertainty about the cure of the disease, economic burden, social stigma, isolation by the family are all the other contributing factors for anxiety and depression. Depression and anxiety may hinder cancer treatment and recovery, as well as the quality of life and survival. We argue that more research is needed to prevent and treat comorbid depression and anxiety among people with cancer and that it requires greater clinical priority [3].

COVID-19 (coronavirus disease 2019) is an infectious disease caused by severe acute respiratory syndrome coronavirus 2 (SARS-CoV-2), previously known as the 2019 novel coronavirus (2019-nCoV), a strain of coronavirus. The first cases were seen in Wuhan, China, in late December 2019 before spreading globally. It was officially recognized as a pandemic by WHO on 11 March 2020. The pandemic has affected people of all nations, continents, races, and socioeconomic groups. The strategies adopted for containment of COVID 19, such as lockdown of the entire communities, quarantining, social isolation, the closing of schools etc. have drastically changed daily life. Kerala, a state in south-west India, has a population of approximately 3.48 crores and there is pride among a large section of people in Kerala that the state's social indicators are at par with those of Nordic countries. This state has once again become a model in the health care battling COVID 19. The early strategic move by the Government has reflected in low case fatality rates and high recovery rates, which is $0.59 \%$ and 96.03\% respectively after 100 days of the outbreak in the state.

COVID 19 pandemic occurring during the treatment of cancer is as if being between Scylla and Charybdis. Common reactions to this disease are the worry about protecting from the virus, because they are at more risk of infection and mortality, concern about the routine cancer care or community-based services which may be disrupted due to treatment, facility closures or reductions in ser- 
vices and lack of public transport due to lockdown. For a treating oncologist, this presents an unprecedented crisis. Pandemic leads him to another level of thinking. He is forced to rethink and adapt the current oncology practice wisely with the provision of high-quality care. The entire health care system is under enormous pressure to deal with this constantly evolving crisis. During this pandemic cancer, patients are likely to feel isolated. There will be increased uncertainty, a period of massive upheaval and a lot of things are not under human control. For cancer patients who have recently commenced on treatment, this pandemic presents a new dimension of a threat to his or her life. In this study, we aim to evaluate whether anxiety and depression have increased and whether this pandemic is a real concern for our cancer patients.

The Hospital Anxiety and Depression Scale (HADS) was devised 30 years ago by Zigmond and Snaith to measure anxiety and depression in a general medical population of patients [4]. It is a self-assessment questionnaire comprising seven questions each for anxiety and depression, which is scored separately and hardly need 2 - 5 min to complete. For both the scales, a score of $\leq 7$ is Normal, 8 - 10 is borderline and $11-21$ is abnormal. This tool is used in our study.

\section{Methods}

This study was conducted in the Department of Radiotherapy and Oncology of Government Medical College, Trivandrum in State of Kerala, India. This institution is a tertiary cancer centre of the State. This study was approved by the scientific Institutional Review Board and by the Human ethical committee.

The primary objective is to assess the hospital prevalence of Anxiety disorder and depression in Cancer patients during COVID 19 pandemic. The secondary objective is to study the major risk factors for anxiety \& depression in cancer patients in this setting.

This is a single institutional cross-sectional prospective study of cancer patients who were diagnosed to have cancer from October 2020 to Dec 2020. This study period represents an immediate 3 month period before COVID 19 outbreak was confirmed and the study participants were on treatment during the study. The study was conducted in April/May 2020. These selection criteria were made to make sure that these patients had their cancer diagnosis before COVID 19 and to assess how this outbreak might have influenced them psychologically. All consecutive patients reporting for treatment during this period and willing to participate in the study were recruited. Patients with a previous history of psychiatric illness and those not on any active cancer treatment were excluded. Illiterate patients and patients who are unable to read and comprehend the local language Malayalam were also excluded.

After getting informed consent from the patients, the HADS questionnaire in the local language was distributed to the participants, face to face, in the waiting room of the OPD clinic. It was confirmed that the individual understood all the questions before answering them. If they did not understand a question, then it 
was explained to them. The participants did not have prior knowledge about the researcher or their interest in the study. The questionnaire was not returned to the participants for comment or correction of answers.

Statistical analysis was done using SPSS software version 21 .

\section{Findings}

A total of 208 patients satisfying the selection criteria were included in this study (Tables 1-6).

\section{Interpretation}

Of the total 208 cancer patients recruited for the study, the major share 132 (63.5\%) patients were female. The mean age of the study population was $56.2 \mathrm{yrs}$ with Standard deviation 10.9. Majority of the patients (72.1\%) were below the poverty line and remaining belonged to the above poverty line socio economic category. As the department caters adult population, almost $98 \%$ of the participants were married and they all have a proper care taker. It is alarming to observe that more than three fourth $(72.6 \%)$ of individuals this study are diabetic whereas prevalence rate of diabetes is only $16 \%-20 \%$ in the general population in Kerala [5]. This is same with the case of hypertension also, which is $78.8 \%$ in the study group while in general population it is 54.5\% [6]. The high rate of hypertension and Diabetes mellitus in the study group may be because majority of the patients are middle aged and elderly.

Breast cancer was the most common type of cancer (43.8\%) followed by lung (23\%), Colo-rectum (20\%). Head \& Neck cancer formed only $18 \%$, which is contrary to the usual scenario. Low number of head \& Neck cases may be due to the limited number of patients seen in ENT department due to COVID 19.60\% of the study belong to advanced stage (Stage III \& IV) and the remaining $40 \%$ was early stage (stage I \& II). Chemotherapy was the main treatment modality (60\%) for this heterogeneous study group followed by chemo radiation (36\%) and radiation $(2.4 \%)$.

Being the period of COVID 19 pandemic, an awareness and psychological aspects with respect to infection was also evaluated with the prepared questionnaire. $100 \%$ of the study group were aware about Corona outbreak of which 92.8\% came to know about this through the media while a small percentage (7.2\%) from friends and relatives. High literacy rate and active politics among people of Kerala keep them socially aware. When an enquiry was made with respect to any worry regarding the COVID 19 , surprisingly it was noted that majority (88.5\%) had no worry regarding it. A minority (11.5\%) who had worry, it was because of the apprehension regarding the continuity of their ongoing cancer treatment and contagious nature of the COVID.

HADS-A and HADS-D score were calculated for all the 208 patients. The overall prevalence rate of anxiety was $7.2 \%$ with borderline cases $4.3 \%$ and abnormal cases $2.9 \%$. With regard to depression, overall prevalence was rate $5.3 \%$ 
Table 1. Base line characteristics of the patients.

\begin{tabular}{|c|c|c|}
\hline Variable & Frequency & Percentage \\
\hline \multicolumn{3}{|l|}{ Age of the patient } \\
\hline$<41$ & 13 & 6.3 \\
\hline $41-50$ & 55 & 26.4 \\
\hline $51-60$ & 60 & 28.8 \\
\hline $61-70$ & 61 & 29.3 \\
\hline $71-80$ & 17 & 8.2 \\
\hline$>81$ & 2 & 1.0 \\
\hline \multicolumn{3}{|l|}{ Gender } \\
\hline Female & 132 & 63.5 \\
\hline Male & 76 & 36.5 \\
\hline \multicolumn{3}{|l|}{ Socio Economic Status } \\
\hline Above poverty line (APL) & 58 & 27.9 \\
\hline Below Poverty Line (BPL) & 150 & 72.1 \\
\hline \multicolumn{3}{|l|}{ Married status } \\
\hline Married & 203 & 97.6 \\
\hline Unmarried & 4 & 1.9 \\
\hline Divorced & 1 & 0.5 \\
\hline \multicolumn{3}{|l|}{ Proper care taker present } \\
\hline Yes & 207 & 99.5 \\
\hline No & 1 & 0.5 \\
\hline \multicolumn{3}{|l|}{ Religion } \\
\hline Hindu & 166 & 79.8 \\
\hline Muslim & 32 & 15.4 \\
\hline Christian & 10 & 4.8 \\
\hline \multicolumn{3}{|l|}{ Family h/o malignancy } \\
\hline Yes & 3 & 1.4 \\
\hline No & 205 & 98.6 \\
\hline \multicolumn{3}{|l|}{ Co morbidities } \\
\hline Hypertension & 164 & 78.8 \\
\hline Diabetes Mellitus & 151 & 72.6 \\
\hline Hypothyroidism & 10 & 4.8 \\
\hline Hyperlipidemia & 9 & 4.3 \\
\hline Coronary Artery disease & 7 & 3.4 \\
\hline Other Co morbidities & 14 & 6.7 \\
\hline
\end{tabular}


Table 2. Treatment characteristics of the patients.

\begin{tabular}{|c|c|c|}
\hline Variable & Frequency & Percentage \\
\hline \multicolumn{3}{|l|}{ Disease site } \\
\hline Breast cancer & 91 & 43.8 \\
\hline Lung cancer & 23 & 11.1 \\
\hline Colorectal cancer & 20 & 9.6 \\
\hline Head \& Neck cancer & 18 & 8.7 \\
\hline Hematological-lymphoid & 10 & 4.8 \\
\hline Multiple myeloma & 10 & 4.8 \\
\hline Gastric Cancer & 8 & 3.8 \\
\hline Hepato-biliary cancer & 7 & 3.4 \\
\hline Gynecological Cancer & 7 & 3.4 \\
\hline Urological Malignancy & 4 & 1.9 \\
\hline Pancreas & 3 & 1.4 \\
\hline Prostate & 3 & 1.4 \\
\hline Esophagus & 1 & 0.5 \\
\hline Soft tissue sarcoma & 1 & 0.5 \\
\hline Testicular malignancy & 1 & 0.5 \\
\hline Others & 1 & 0.5 \\
\hline \multicolumn{3}{|l|}{ Stage } \\
\hline I & 14 & 6.7 \\
\hline II & 54 & 26.0 \\
\hline III & 66 & 31.7 \\
\hline IV & 59 & 28.4 \\
\hline Not available & 15 & 7.2 \\
\hline \multicolumn{3}{|l|}{ Planned treatment } \\
\hline Chemotherapy & 126 & 60.6 \\
\hline Radiotherapy & 5 & 2.4 \\
\hline Surgery & 2 & 1.0 \\
\hline Combined modality & 75 & 36.4 \\
\hline
\end{tabular}




\section{Continued}

Default of treatment - COVID period

$\begin{array}{lcc}\text { Yes } & 46 & 22.1 \\ \text { No } & 162 & 77.9\end{array}$

\begin{tabular}{|c|c|c|}
\hline No & 162 & 77.9 \\
\hline \multicolumn{3}{|l|}{ Duration of default (Weeks) } \\
\hline$<1$ & 5 & 10.9 \\
\hline $1-2$ & 15 & 32.6 \\
\hline $2-3$ & 17 & 36.9 \\
\hline $3-4$ & 2 & 4.3 \\
\hline $4-5$ & 6 & 13.0 \\
\hline 8 week & 1 & 2.1 \\
\hline \multicolumn{3}{|l|}{ Reason for default } \\
\hline Lack of conveyance (lock down due to COVID) & 43 & 93.5 \\
\hline Fear of COVID infection & 1 & 2.2 \\
\hline Personal/family reasons (unrelated to COVID) & 2 & 4.3 \\
\hline \multicolumn{3}{|l|}{ Worried about treatment default } \\
\hline Yes & 11 & 23.9 \\
\hline No & 35 & 76.1 \\
\hline
\end{tabular}

Table 3. HADS scale assessment of Anxiety (HADS-A).

\begin{tabular}{ccc}
\hline Category & Frequency & Percentage \\
\hline Normal & 193 & 92.8 \\
Borderline & 9 & 4.3 \\
Abnormal & 6 & 2.9
\end{tabular}

Table 4. HADS scale assessment of Depression (HADS-D).

\begin{tabular}{ccc}
\hline Category & Frequency & Percentage \\
\hline Normal & 197 & 94.7 \\
Borderline & 7 & 3.4 \\
Abnormal & 4 & 1.9 \\
\hline
\end{tabular}


A. S. Anand et al.

Table 5. Risk factor assessment for Anxiety.

\begin{tabular}{|c|c|c|c|c|c|c|c|c|c|c|}
\hline \multirow{3}{*}{ Characteristic } & & \multicolumn{4}{|c|}{ Anxiety } & \multirow{2}{*}{\multicolumn{2}{|c|}{ Total }} & \multirow{3}{*}{$\chi^{2}$} & \multirow{3}{*}{ Df } & \multirow{3}{*}{$\mathrm{p}$} \\
\hline & & \multicolumn{2}{|c|}{ Yes } & \multicolumn{2}{|c|}{ No } & & & & & \\
\hline & & $\mathrm{n}$ & $\%$ & $\mathrm{n}$ & $\%$ & $\mathrm{n}$ & $\%$ & & & \\
\hline \multirow{3}{*}{ Age in years } & $<50$ & 7 & 10.3 & 61 & 89.7 & 68 & 100 & & & \\
\hline & $51-60$ & 3 & 5 & 57 & 95 & 60 & 100 & & & \\
\hline & $>60$ & 5 & 6.3 & 75 & 93.8 & 80 & 100 & 1.515 & 2 & 0.469 \\
\hline \multirow{2}{*}{ Gender } & Male & 3 & 3.9 & 73 & 96.1 & 76 & 100 & & & \\
\hline & Female & 12 & 9.1 & 120 & 90.9 & 132 & 100 & 1.907 & 1 & 0.167 \\
\hline \multirow{2}{*}{ Economic status } & APL & 2 & 3.4 & 56 & 96.6 & 58 & 100 & & & \\
\hline & BPL & 13 & 8.7 & 137 & 91.3 & 150 & 100 & 1.702 & 1 & 0.192 \\
\hline \multirow{16}{*}{ Site } & Breast & 8 & 8.8 & 83 & 91.2 & 91 & 100 & & & \\
\hline & Lung & 3 & 13 & 20 & 87 & 23 & 100 & & & \\
\hline & Esophagus & 0 & 0 & 1 & 100 & 1 & 100 & & & \\
\hline & Gastric & 0 & 0 & 8 & 100 & 8 & 100 & & & \\
\hline & Colo-rectum & 0 & 0 & 20 & 100 & 20 & 100 & & & \\
\hline & Head \& Neck & 1 & 5.6 & 17 & 94.4 & 18 & 100 & & & \\
\hline & Pancreas & 0 & 0 & 3 & 100 & 3 & 100 & & & \\
\hline & Hepato-biliary & 1 & 14.3 & 6 & 85.7 & 7 & 100 & & & \\
\hline & Gynec & 2 & 28.6 & 5 & 71.4 & 7 & 100 & & & \\
\hline & Prostate & 0 & 0 & 3 & 100 & 3 & 100 & & & \\
\hline & Urology & 0 & 0 & 4 & 100 & 4 & 100 & & & \\
\hline & Hematological & 0 & 0 & 10 & 100 & 10 & 100 & & & \\
\hline & Sarcoma & 0 & 0 & 1 & 100 & 1 & 100 & & & \\
\hline & Myeloma & 0 & 0 & 10 & 100 & 10 & 100 & & & \\
\hline & Testis & 0 & 0 & 1 & 100 & 1 & 100 & & & \\
\hline & Others & 0 & 0 & 1 & 100 & 1 & 100 & 11.697 & 15 & 0.702 \\
\hline \multirow{5}{*}{ Stage } & Stage I & 2 & 14.3 & 12 & 85.7 & 14 & 100 & & & \\
\hline & Stage II & 3 & 5.6 & 51 & 94.4 & 54 & 100 & & & \\
\hline & Stage III & 4 & 6.1 & 62 & 93.9 & 66 & 100 & & & \\
\hline & Stage IV & 6 & 10.2 & 53 & 89.8 & 59 & 100 & & & \\
\hline & NA & 0 & 0 & 15 & 100 & 15 & 100 & 3.336 & 4 & 0.503 \\
\hline \multirow{3}{*}{ HPR } & Squamous & 1 & 4.2 & 23 & 95.8 & 24 & 100 & & & \\
\hline & Adeno/breast & 14 & 9.3 & 136 & 90.7 & 150 & 100 & & & \\
\hline & Others & 0 & 0 & 34 & 100 & 34 & 100 & 3.984 & 2 & 0.136 \\
\hline \multirow{3}{*}{ Reason for worry } & Cancer & 15 & 7.9 & 174 & 92.1 & 189 & 100 & & & \\
\hline & COVID & 0 & 0 & 2 & 100 & 2 & 100 & & & \\
\hline & Both & 0 & 0 & 17 & 100 & 17 & 100 & 1.625 & 2 & 0.444 \\
\hline \multirow{2}{*}{ Default of treatment } & Yes & 2 & 4.3 & 44 & 95.7 & 46 & 100 & & & \\
\hline & No & 13 & 8 & 149 & 92 & 162 & 100 & 0.724 & 1 & 0.395 \\
\hline
\end{tabular}


Table 6. Risk factor assessment for depression.

\begin{tabular}{|c|c|c|c|c|c|c|c|c|c|c|}
\hline \multirow{3}{*}{ Characteristic } & & \multicolumn{4}{|c|}{ Depression } & \multirow{2}{*}{\multicolumn{2}{|c|}{ Total }} & \multirow{3}{*}{$x^{2}$} & \multirow{3}{*}{$\mathrm{df}$} & \multirow{3}{*}{$\mathrm{P}$} \\
\hline & & \multicolumn{2}{|c|}{ Yes } & \multicolumn{2}{|c|}{ No } & & & & & \\
\hline & & $\mathrm{n}$ & $\%$ & $\mathrm{n}$ & $\%$ & $\mathrm{n}$ & $\%$ & & & \\
\hline \multirow{3}{*}{ Age in years } & $<50$ & 3 & 4.4 & 65 & 95.6 & 68 & 100 & & & \\
\hline & $51-60$ & 3 & 5 & 57 & 95 & 60 & 100 & & & \\
\hline & $>60$ & 5 & 6.3 & 75 & 93.8 & 80 & 100 & 0.262 & 2 & 0.877 \\
\hline \multirow{2}{*}{ Sex } & Male & 4 & 5.3 & 72 & 94.7 & 76 & 100 & & & \\
\hline & Female & 7 & 5.3 & 125 & 94.7 & 132 & 100 & 0 & 1 & 0.99 \\
\hline \multirow{2}{*}{ Socio economic status } & APL & 1 & 1.7 & 57 & 98.3 & 58 & 100 & & & \\
\hline & BPL & 10 & 6.7 & 140 & 93.3 & 150 & 100 & 2.04 & 1 & 0.153 \\
\hline \multirow{16}{*}{ Site of cancer } & Breast & 4 & 4.4 & 87 & 95.6 & 91 & 100 & & & \\
\hline & Lung & 1 & 4.3 & 22 & 95.7 & 23 & 100 & & & \\
\hline & Esophagus & 0 & 0 & 1 & 100 & 1 & 100 & & & \\
\hline & Gastric & 1 & 12.5 & 7 & 87.5 & 8 & 100 & & & \\
\hline & Colo-rectum & 0 & 0 & 20 & 100 & 20 & 100 & & & \\
\hline & Head \& Neck & 3 & 16.7 & 15 & 83.3 & 18 & 100 & & & \\
\hline & Pancreas & 0 & 0 & 3 & 100 & 3 & 100 & & & \\
\hline & Hepato-biliary & 0 & 0 & 7 & 100 & 7 & 100 & & & \\
\hline & Gynecological & 1 & 14.3 & 6 & 85.7 & 7 & 100 & & & \\
\hline & Prostate & 0 & 0 & 3 & 100 & 3 & 100 & & & \\
\hline & Urological & 1 & 25 & 3 & 75 & 4 & 100 & & & \\
\hline & Hematological & 0 & 0 & 10 & 100 & 10 & 100 & & & \\
\hline & Sarcoma & 0 & 0 & 1 & 100 & 1 & 100 & & & \\
\hline & Myeloma & 0 & 0 & 10 & 100 & 10 & 100 & & & \\
\hline & Testicular & 0 & 0 & 1 & 100 & 1 & 100 & & & \\
\hline & Others & 0 & 0 & 1 & 100 & 1 & 100 & 13.086 & 15 & 0.596 \\
\hline \multirow{5}{*}{ Stage } & Stage I & 1 & 7.1 & 13 & 92.9 & 14 & 100 & & & \\
\hline & Stage II & 0 & 0 & 54 & 100 & 54 & 100 & & & \\
\hline & Stage III & 5 & 7.6 & 61 & 92.4 & 66 & 100 & & & \\
\hline & Stage IV & 5 & 8.5 & 54 & 91.5 & 59 & 100 & & & \\
\hline & NA & 0 & 0 & 15 & 100 & 15 & 100 & 5.834 & 4 & 0.212 \\
\hline \multirow{3}{*}{ HPR } & SCC & 3 & 12.5 & 21 & 87.5 & 24 & 100 & & & \\
\hline & $\mathrm{AC}$ & 7 & 4.7 & 143 & 95.3 & 150 & 100 & & & \\
\hline & Others & 1 & 2.9 & 33 & 97.1 & 34 & 100 & 2.982 & 2 & 0.225 \\
\hline \multirow{3}{*}{ Reason for worry } & Cancer & 9 & 4.8 & 180 & 95.2 & 189 & 100 & & & \\
\hline & COVID & 0 & 0 & 2 & 100 & 2 & 100 & & & \\
\hline & Equally & 2 & 11.8 & 15 & 88.2 & 17 & 100 & 1.64 & 2 & 0.44 \\
\hline \multirow{2}{*}{ Defaulted treatment } & Yes & 1 & 2.2 & 45 & 97.8 & 46 & 100 & & & \\
\hline & No & 10 & 6.2 & 152 & 93.8 & 162 & 100 & 1.144 & 1 & 0.285 \\
\hline
\end{tabular}


with $3.4 \%$ borderline \& $1.9 \%$ abnormal cases. The prevalence of the psychological morbidity among cancer patients from different sectors are shown in Table 7.

Our study is having one of the least prevalence rates. In this context, it may be noted that the rates vary with respect to the evaluation tool used, tumour site studied, ethnicity, the status of the population at the time of study viz. whether it is the time of diagnosis or during treatment or follow up.

Our study population is from the state of Kerala in India, where health indicators are at par with that of a developed country. All patients were evaluated during their treatment period. Another study from Kerala has shown that the prevalence rate range between $19 \%$ - 20\% [7] and from other states in India as $28 \%-37 \%$. Data from other countries also show varying data, as low as $7 \%$ to as high as $48 \%$. We have addressed the issue of psychological distress in our cancer patients specifically in COVID pandemic period, with a hypothesis of increased prevalence. But our results reveal that the rate is comparatively low.

This probably is due to two main reasons. First of all, during COVID outbreak as a part of COVID containment strategies, the health sector is in full swing. Government has taken steps to make sure that all patients are taken care even at the grass-root level and it may also be noted at this juncture that the primary health care in Kerala is strong. This protective feel of patients on the robust health system of Kerala might bring down the anxiety of patients. For example,

Table 7. Prevalence of the psychological morbidity among cancer patients from different sectors.

\begin{tabular}{|c|c|c|c|c|}
\hline Study & $\begin{array}{l}\text { Prevalence } \\
\text { of anxiety }\end{array}$ & $\begin{array}{c}\text { Prevalence } \\
\text { of depression }\end{array}$ & Country & Study Tool \\
\hline $\begin{array}{l}\text { Reliability \& validity of the Malayalam hospital } \\
\text { anxiety \& depression scale (HADS) in } \\
\text { cancer patients, Thomas et al. [7] }\end{array}$ & $19 \%$ & $20.6 \%$ & $\begin{array}{l}\text { Kerala, } \\
\text { India }\end{array}$ & HADS \\
\hline $\begin{array}{l}\text { Prevalence of depression and anxiety disorder } \\
\text { in cancer patients: An institutional } \\
\text { experience, Shankar et al. [2] }\end{array}$ & $35.4 \%$ & $37.5 \%$ & India & $\begin{array}{c}\text { Patient health Questionnaire-9 } \\
\text { (PHQ-9) Generalized Anxiety } \\
\text { Disorder-7 Scale }\end{array}$ \\
\hline $\begin{array}{c}\text { Study of Anxiety and Depression among } \\
\text { Breast Cancer patients from North India } \\
\text { Vivek Srivastava et al. [8] }\end{array}$ & $37.0 \%$ & $28.0 \%$ & India & HADS \\
\hline $\begin{array}{c}\text { Prevalence of depression and anxiety } \\
\text { among cancer patients. Novin Nikbakhsh } \\
\text { et al. [9] }\end{array}$ & $46.0 \%$ & $48.0 \%$ & Iran & HADS \\
\hline $\begin{array}{l}\text { A Study of Depression and Anxiety in } \\
\text { Cancer Patients, Thapa P et al. [10] }\end{array}$ & $40.0 \%$ & $28.0 \%$ & Nepal & HADS \\
\hline $\begin{array}{l}\text { Emotional distress in cancer patients: the } \\
\text { Edinburgh Cancer Centre symptom study, } \\
\text { V Strong et al. [11] }\end{array}$ & $23.0 \%$ & $16.0 \%$ & Edinburgh, UK & HADS \\
\hline
\end{tabular}


the Government has even taken steps to provide oral chemotherapeutic medications or hormonal therapies at the doorsteps incorporating the primary health care and the Home department. Same time, systemic chemotherapeutic facilities were made available in the outreach Government hospitals like taluk or district hospitals. This might have benefitted a subset of patients and such measures are likely to alleviate stress and boost confidence. To cope up with the aspect of mental health, a psychological support team was also instituted. Many strategies were devised to manage stress and other mental health concerns arising from the outbreak. These strategies taken by the Government seems a step ahead and a recent article by Prof Emily et al. [12] stresses the need for such strategies for timely mental health care in a pandemic.

The second aspect may be the fact that this set of patients are in the cancer treatment period, hence they have already made multiple visits to Oncologist. Hence, the assurance and the feel of the patient that they are getting a definitive treatment will again decrease the tension.

We have not included patients on pure palliative treatment and not on oncological treatment. The mental makeup of a patient getting a palliative treatment may be different. This may be another reason for a low rate in our study compared to the studies which have incorporated this group of patients.

Risk factors for anxiety and depression were also evaluated in our study. Variables like age, sex, socioeconomic status, primary site, stage of the disease and default of disease were examined for risk association and none had a statistical significance.

An evaluation was done to see whether COVID19 outbreak is a contributing factor for anxiety and depression. All the participants were asked what worries them the most whether "Cancer" or "COVID 19" or "both" or "none". 189 (90.9\%) said it is the "cancer" that worries them the most, 17 (8.2\%) opined that "both cancer \& COVID" and 2 (1\%) said it is "COVID". None of the patients who had anxiety as per the HADS criteria has opined that "COVID" is a worrying factor. Two patients with depression said that "both" are worrisome and for all others again "Cancer". Thus "COVID 19" is not a reason for anxiety in this study group. This lack of impact of "COVID 19" on the psychological aspect of the study group may be because, in Kerala, at the time of the conduct of this study, COVID 19 pandemic is well contained, R0 (R nought) 0.45 and the case fatality is one of the lowest in the world.

\section{Conclusion}

The prevalence of anxiety and depression among cancer patients varies among patients regionally and may be multifactorial. Cancer disease per se is the most worrisome factor and a pandemic like COVID19 though dreadful for the public; the psychological influence of it on cancer patients has not increased on the contrary. Interventions taken by Government to foster collective solidarity in beating COVID might have positively prevented the increase of this psychologi- 
cal distress.

\section{Conflicts of Interest}

The authors declare no conflicts of interest regarding the publication of this paper.

\section{References}

[1] Tiwari, A. (2018) Prevalence of Depression and Anxiety among Cancer Patients in Small Town in India: Single Centre Study. International Journal of Radiation Oncology •Biology • Physics, 103, No. 4. https://doi.org/10.1016/j.ijrobp.2018.11.060

[2] Shankar, A., Dracham, C., Ghoshal, S. and Grover, S. (2016) Prevalence of Depression and Anxiety Disorder in Cancer Patients: An Institutional Experience. Indian Journal of Cancer, 53, 432-434.

[3] Niedzwiedz, C.L., Knifton, L., Robb, K.A., et al. (2019) Depression and Anxiety among People Living with and beyond Cancer: A Growing Clinical and Research Priority. BMC Cancer, 19, 943. https://doi.org/10.1186/s12885-019-6181-4

[4] Zigmond, A.S. and Snaith, R.P. (1983) The Hospital Anxiety and Depression Scale. Acta Psychiatrica Scandinavica, 67, 361-370. https://doi.org/10.1111/j.1600-0447.1983.tb09716.x

[5] Thankappan, K.R., Shah, B., Mathur, P., et al. (2010) Risk Factor Profile for Chronic Non-Communicable Diseases: Results of a Community-Based Study in Kerala, India. Indian Journal of Medical Research, 131, 53-63.

[6] Zachariah, M.G., Thankappan, K.R., Alex, S.C., Sarma, P.S. and Vasan, R.S. (2003) Prevalence, Correlates, Awareness, Treatment, and Control of Hypertension in a Middle-Aged Urban Population in Kerala. Indian Heart Journal, 55, 245-251.

[7] Thomas, B.C., Devi, N., Sarita, G.P., et al. (2005) Reliability and Validity of the Malayalam Hospital Anxiety and Depression Scale (HADS) in Cancer Patients. Indian Journal of Medical Research, 122, 395-399.

[8] Srivastava, V., Ansari, M.A., Kumar, A., Shah, A.G., Meena, R.K., Sevach, P. and Singh, O.P. (2016) Study of Anxiety and Depression among Breast Cancer patients from North India. Clinical Psychiatry, 2, No. 1. https://doi.org/10.21767/2471-9854.100017

[9] Nikbakhsh, N., Moudi, S., Abbasian, S. and Khafri, S. (2014) Prevalence of Depression and Anxiety among Cancer Patients. Caspian Journal of Internal Medicine, 5 , $167-170$

[10] Thapa, P., Rawal, N. and Bista, Y. (2010) A Study of Depression and Anxiety in Cancer Patients. Nepal Medical College Journal, 12, 171-175.

[11] Strong, V., Waters, R., Hibberd, C., et al. (2007) Emotional Distress in Cancer Patients: The Edinburgh Cancer Centre Symptom Study. British Journal of Cancer, 96, 868-874. https://doi.org/10.1038/sj.bjc.6603626

[12] Holmes, E.A., O'Connor, R.C., Perry, V.H., Tracey, I., Wessely, S., Arseneault, L., et al. (2020) Multidisciplinary Research Priorities for the COVID-19 Pandemic: A Call for Action for Mental Health Science. The Lancet: Psychiatry, 7, 547-560. https://doi.org/10.1016/S2215-0366(20)30168-1 